\title{
Populismus: rechtsverschobener Klassenkampf
}

Populismus ist eine Methode, das politische Feld radikal zu vereinfachen, indem man "das" (homogen gedachte) Volk gegen „die“ (pauschal negierte) politische Klasse und generell die Eliten auffährt. Mit derart simplen Feindbildern sind seit dem 19. Jahrhundert besonders in ökonomischen und kulturellen Krisenlagen Konflikte inszeniert worden. Die Methode wurde mit unterschiedlichen Inhalten gefüllt - links in Kategorien des Klassenkampfs gegen „die da oben“, rechts in Konfrontation mit „denen da“, d. h. Fremden und Minderheiten. Bisweilen haben sich beide Tendenzen amalgamiert, wenn etwa ausländische Arbeitskräfte in diskriminierenden Worten und Bildern als lohndrückende Konkurrenz dargestellt wurden. Populismus, der Solidarität mit den „kleinen Leuten“ vorgaukelt, ist in Wahrheit ein Motor der Entsolidarisierung.

Populismus mag als Schlagwort im politischen Kampf taugen, als analytische Kategorie taugt er nicht. Inhalt des aktuellen Rechtspopulismus ist ein völkisch-autoritärer Nationalismus. Als „Volk“ wird dabei nicht eine sozioökonomische Unterschichten-Population begriffen, vielmehr suggerieren ethnische Konstrukte (,Bio-Deutsche“, „Francais de souche" etc.) eine homogene Herkunfts- und Abstammungsgemeinschaft mit langer Geschichte und solidem Identitätskern. Diesem Volk (und nicht dem pluralen, in der Regel uneinigen „Demos“) wird eine über den Institutionen stehende Autorität zugewiesen - „das Volk steht über dem Recht“, besagte etwa ein Slogan der österreichischen Freiheitlichen. Und in dieser Sichtweise wird das Volk auch nicht in den Instanzen der repräsentativen Demokratie vertreten, eher formt es sich als Bewegungskörper hinter charismatischen Führerpersönlichkeiten, die per Plebiszit legitimiert werden. Das Menschen- und Gesellschaftsbild rechter Bewegungen ist zutiefst autoritär, in der Regel auch patriarchal und homophob. Die eigene, ethnisch definierte Nation wird ins Zentrum gerückt (America first!, La France d'abord etc.), aber aggressiv ist dieser Nationalismus (bisher) weniger nach außen als nach innen gegen vermeintliche Volksfeinde, wie nicht nur Donald Trump demokratische Oppositionelle bezeichnet, und gegen Fremde, die Ansprüche auf Gleichberechtigung und Gleichbehandlung stellen.

Oft wird der „Populismus“ als Ausdruck einer materiellen Misere gesehen und gerechtfertigt. Doch weniger in der Schlechterstellung bei Status, Einkommen und Lebenschancen liegt der Beweggrund des völkisch-autoritären Nationalismus als vielmehr in der barschen Zurückweisung menschenrechtlich begründeter Anwartschaften auf Teilhabe am Reichtum reicher Gesellschaften, die ihre Ressourcen nicht zuletzt durch neokoloniale Abhängigkeiten erwirtschaften und ihre Emissionen und Kosten in den "globalen Süden" externalisieren. Schon die Republikaner (REP) haben in den 1980er Jahren eine solche Strategie des "Wohlstandschauvinismus" verfolgt, der sich mit der Intensivierung der Flüchtlingsströme verstärkt hat und nun gewaltförmige Abstoßungen hervorbringt. Flüchtlingsabwehr, Islamfurcht und die Ablehnung von Minoritäten, das monomane Themendreieck der Rechten, mögen ökonomisch unterfüttert sein, ihre Antriebe sind aber wesentlich kultureller Natur, bis hin zum blanken Rassismus.

Das Gros der Anhänger und Wähler völkisch-autoritärer Parteien (übrigens vor allem männlichen Geschlechts) ist mittelständisch-wohlsituiert, man findet unter innen aber ebenso Bezieher relativ niedriger Einkommen mit geringer Qualifikation in bedrohten Beschäftigungsverhältnissen. Bei innen sind Ängste vor Wohlstandsverlust und massive Aversionen gegen eine gnadenlos wirkende wirtschaftliche Globalisierung entstanden, auch Unmut über eine Rhetorik der Alternativlosigkeit, derer sich nicht zuletzt sozialdemokratische Regierungen befleißigt haben. Ohne Zweifel ist die au- 
toritäre Welle auch eine Reaktion auf die seit 2008 gestiegene innergesellschaftliche Ungleichheit, mehr noch auf ein Gefühl der Marginalisierung im „Hinterland“ großer urbaner Agglomerationen, namentlich in deindustrialisierten und ländlichen Regionen mit spärlicher Infrastruktur. Heimatverbundene „Somewheres“ bringen (angeblich wurzellosen) „Anywheres“ Ressentiments entgegen, die durch Transferzahlungen schwer zu beseitigen sind.

Anders als in der Geschichte der sozialen Bewegungen des 19. und frühen 20. Jahrhunderts lösen solche Deprivationen keine linke Reaktion aus und führen selten zur Unterstützung sozialistischer Reform- und Revolutionsanstrengungen. Dominant ist ein völkisches Narrativ, das bereits der Faschismus des 20. Jahrhunderts an die Stelle linker Sozialutopien setzte. Es grassieren antisemitische Verschwörungstheorien (exemplarisch gegen den ungarisch-amerikanischen Finanzinvestor George Soros) und Dystopien des „großen Bevölkerungsaustauschs“ (Renaud Camus) oder der „Umvolkung“ (Björn Höcke), einer angeblich von EU-Regierungen verfolgten systematischen Ersetzung christlich-weißer Bevölkerungen durch Muslime, Afrikaner und Asiaten. Das Programm der neuen Rechten läuft letztlich auf ethnische Säuberungen hinaus. Für dieses Revirement gibt es historische Vorbilder im „Nationalsozialismus“ der NSDAP, der eben deshalb als „Fliegenschiss“ (Alexander Gauland) geschichtspolitisch verdrängt werden soll. Auch in den USA sind in der Ära Trump extreme Strömungen der „White Supremacy“ in den Mainstream eingegangen. Beklagt wird auch hier der Verlust der demografischen Mehrheit und religiös-kulturellen Hegemonie weißer Menschen vor allem anglo-europäischen Ursprungs, was sich in den USA vor allem gegen Latinos und Hispanics richtet, die mit einer Mauer an der mexikanischen Grenze und rigiden Abschreckungs- und Internierungsmaßnahmen von den USA ferngehalten werden sollen.

Wirtschafts- und sozialpolitisch verfolgten Front National, die Freiheitsparteien von Geert Wilders und Jörg Haider und die skandinavischen Rechtsparteien ursprünglich einen „neoliberalen“ Kurs, mit dem Ziel, den Wohlfahrtsstaat zu schrumpfen; zuletzt sind sie zur menschen- und verfassungsrechtlich problematischen Präferenz der ethnischen Eigengruppe übergegangen - wie die PiS-Regierung in Polen mit Kindergeldauszahlungen an „Bio-Polen“ und die ungarische Regierung mit einer „nativistischen“ Politik der Geburtenförderung. Auch in Deutschland propagieren Teile des radikalen AfD-,,Flügels“ das Programm eines „,nationalen Sozialismus“, während die Gesamtpartei weiterhin neoliberal ausgerichtet ist. In Österreich und Ungarn haben Freiheitliche und Fidesz arbeitnehmerfeindliche Arbeitszeitregelungen durchgebracht. Partiell relativiert sich damit die überkommene Spaltungs- und Konfliktlinie zwischen Links und Rechts, die den sozialstrukturellen Gegensatz von Kapital und Arbeit, Arm und Reich, Ober- und Unterschichten in relativ stabile politische Formationen überführt und auch Präferenzen für liberal-marktwirtschaftliche oder staatsinterventionistische Wirtschafts- und Sozialpolitiken hervorgebracht hat.

Derzeit finden in „Industriegesellschaften“ tektonische Verschiebungen entlang des dargestellten Kulturkonflikts statt. Dieser formt sich auch transnational zum Gegensatz zwischen Kosmopoliten und Kommunitären, die jeweils wirtschaftliche und kulturelle Globalisierung konträr bewerten und in der Regel auch der Europäischen Union skeptisch gegenüberstehen. Wollte man die neue Farbenlehre am deutschen (oder auch österreichischen) Beispiel verdeutlichen, stellt man vor allem bei jüngeren Alterskohorten fest, dass der alte Gegensatz zwischen Schwarz und Rot durch den Konflikt zwischen Grün und Blau verdrängt worden ist. Dabei ist es durchaus kein

Claus Leggewie

Universität Gießen

Claus.Leggewie@zmi.uni-giessen.de
Zufall, wenn das Gros der völkisch-autoritären Rechten am klassischen fossilen Industrialismus festhält, die Existenz des Klimawandels bestreitet und Maßnahmen zu Klima- und Artenschutz verzögert oder hintertreibt. 